\title{
EDUCAÇÃO AMBIENTAL NAS ESCOLAS ESTADUAIS DE FLORESTA (PE)
}

\author{
Maria Aparecida de Sá ${ }^{1}$ \\ Marcondes Albuquerque de Oliveira ${ }^{2}$ \\ Ana Selia Rodrigues Novaes ${ }^{3}$
}

Resumo: A Educação Ambiental vem sendo considerada cada vez mais urgente e de grande relevância para a sociedade atual. Diante disto, foi realizada uma pesquisa de campo, tendo como objetivo analisar como os professores das Escolas Públicas Estaduais de Floresta - PE vem trabalhando as questões ambientais e com qual frequência nas turmas de Ensino Médio. A pesquisa ocorreu com aplicação de questionários, utilizando amostragem aleatória de $10 \%$ dos alunos do Ensino Médio, por adesão; 30\% dos educadores do Ensino Médio e os gestores de cada escola pesquisada, num total de 04 escolas. Foi constatado que a questão ambiental ainda é pouco trabalhada e que existe uma barreira que separa discurso e prática.

Palavras-chave: Educação Ambiental. Meio Ambiente; Sustentabilidade.

${ }^{1}$ IF Sertão (PE), Campus Floresta (PE). E-mail: cidasa66@hotmail.com

${ }^{2}$ Instituto de Tecnologia de Pernambuco. E-mail: marcondesoliveira@yahoo.com.br

${ }^{3}$ IF Sertão (PE), Campus Zona Rural, Petrolina (PE). E-mail: anaselianovaes@hotmail.com

Revbea, São Paulo, V. 10, N 1: 118-126, 2015. 


\section{Introdução}

A educação ambiental pode ser entendida como toda ação educativa que contribui para a formação de cidadãos conscientes da preservação do meio ambiente e apto a tomarem decisões coletivas sobre questões ambientais necessárias para o desenvolvimento de uma sociedade sustentável. É o instrumento eficaz para se conseguir criar e aplicar formas sustentáveis de interação sociedade-natureza. Este é o caminho para que o indivíduo assuma novas atitudes que levem a diminuição da degradação ambiental, promova a melhoria da qualidade de vida e reduza a pressão sobre os recursos naturais.

Sabe-se que, numa sociedade, a escola é considerada o centro de formação humana e profissional do cidadão, e ao lado da família e dos meios de comunicação compartilha a responsabilidade de desenvolver as habilidades e o acesso à informação.

Diante disso, a educação ambiental está relacionada com as áreas de pesquisa, análise, apresentação e conscientização a respeito das necessidades e obrigações com o meio ambiente e com o aprofundamento do conhecimento sobre 0 mesmo, preparando o ser humano para a preservação da natureza e para o uso sustentável de seus recursos.

Portanto, educação ambiental deve ser vista como um processo de permanente aprendizagem que valoriza as diversas formas de conhecimentos, habilidades e competências, visando formar cidadãos comprometidos com a melhoria local e planetária. À medida que adquire novos conhecimentos, o educando, se torna mais capaz de interagir melhor com os seus semelhantes e com o espaço geográfico. Dessa forma, o aprender deve ser um ato de formação contínua, e o termo desenvolvimento sustentável é empregado nessa estratégia com o significado de melhorar a qualidade de vida humana dentro dos limites da capacidade de suporte dos ecossistemas. Para tanto, é importante o fortalecimento das organizações sociais e comunitárias, a redistribuição de recursos mediante parcerias, de informação e capacitação para participar crescentemente dos espaços públicos de decisão e para a construção de instituições pautadas por uma lógica de sustentabilidade.

O desafio político da sustentabilidade, apoiado no potencial transformador das relações sociais que representam o processo da Agenda 21, encontra-se estreitamente vinculado ao processo de fortalecimento da democracia e da construção da cidadania.

A educação ambiental, nas suas diversas possibilidades, abre um estimulante espaço para repensar práticas sociais e o papel dos professores como mediadores e transmissores de um conhecimento necessário para que os alunos adquiram uma base adequada de compreensão essencial do meio ambiente global e local, da independência dos problemas e soluções e da importância da responsabilidade de cada um para construir uma sociedade planetária mais equitativa e ambientalmente sustentável. 


\section{Educação Ambiental: necessária e urgente}

De acordo com a Lei 9.795/99, entende-se por educação ambiental os processos por meio dos quais o indivíduo e a coletividade constroem valores sociais, conhecimentos, habilidades, atitudes e competências voltadas para a conservação do meio ambiente, bem de uso comum do povo, essencial à sadia qualidade de vida e sua sustentabilidade (BRASIL, 2007).

A Educação Ambiental é considerada hoje um processo permanente, no qual os indivíduos e a comunidade tomam consciência do meio ambiente e adquirem os conhecimentos, os valores, as habilidades, as experiências e a determinação que os tornam aptos a agir individual e coletivamente para resolver problemas ambientais presentes e futuros.

Uma das alternativas para a inclusão da temática ambiental no meio escolar é a aprendizagem em forma de projetos, essa é uma proposta alinhada com o novo entendimento do processo de aprendizagem que sugere a necessidade de estratégias de ensino mais adequadas e torna evidente a importância de um currículo integrado que valorize o conhecimento contextual, no qual as várias disciplinas sejam vistas como recursos a serviço de um objeto central. Esse objeto central também pode ser entendido como um tema transversal que permeia as outras disciplinas já constituídas e consegue trazer para a realidade escolar o estudo de problemas do dia a dia.

O princípio da sustentabilidade, segundo Leff (2008), surge no contexto da globalização como a marca de um limite e o sinal que reorienta o processo civilizatório da humanidade. A crise ambiental veio questionar a racionalidade e os paradigmas teóricos que impulsionaram e legitimaram o crescimento econômico, negando a natureza. A sustentabilidade ecológica é um suporte eficaz para se chegar a um desenvolvimento duradouro, questionando as próprias bases de produção.

A Educação Ambiental é um instrumento essencial para poder melhorar os impactos ambientais que tanto vem prejudicando o nosso dia a dia, ela exerce um papel fundamental na formação crítica e atuante dos nossos indivíduos no qual desenvolve uma sociedade de consumo consciente, no intuito de preservar o mesmo.

O aprendizado ambiental é um componente vital, pois oferece motivos que levam os alunos se reconhecerem como parte integrante do meio em que vivem e faz pensar nas alternativas para soluções dos problemas ambientais e ajudar a manter os recursos para as futuras gerações.

Os seres humanos são os únicos animais que transformam a natureza em benefício de sua sobrevivência. No entanto, para atender às necessidades atuais, estamos usando nossa capacidade de modo a tornar o ambiente insustentável para as gerações futuras. Não podemos transformar, sem limites, a natureza. Somos muitos, os recursos da Terra finitos, e nossa tecnologia causa fortes impactos no ambiente: polui o ar e a água, altera o solo, destrói florestas e outros ambientes naturais, transforma a atmosfera, modifica o clima. 
Não é mais possível explorar ilimitadamente os elementos da natureza e causar tantos impactos ambientais. (CARVALHO et al.,2005).

O meio ambiente vem sofrendo grande perda com toda essa produção acelerada e esse consumo desenfreado. É essencial que o ser humano entenda a necessidade de cuidar do ambiente uma vez que toda sobrevivência existente é adquirida através dos recursos oferecidos e que para se formar cidadãos atuantes é preciso formar a consciência dos mesmos e transforma-se em filosofia de vida. A educação ambiental, deve necessariamente transformase em ação.

\section{Pesquisa de Campo sobre a Educação Ambiental}

A Educação Ambiental permite que o processo pedagógico aconteça sob diferentes aspectos, que se complementam uns aos outros. Assim, há um espaço para momentos onde ocorre transmissão de conhecimento, construção do conhecimento e a desconstrução das representações sociais. Com a Educação Ambiental, a escola, os conteúdos e o papel do professor e dos alunos são colocados em uma nova situação, não apenas relacionada com 0 conhecimento, mas sim com o uso que fazemos dele e sua importância para a nossa participação política cotidiana. Portanto, cabe a escola contribuir para o processo de transformação da sociedade atual em uma sociedade sustentável, centrando no exercício responsável da cidadania, que considere a natureza como um bem comum, leve em conta a capacidade de regeneração dos recursos materiais, promova a distribuição equitativa da riqueza gerada $e$ favoreça condições dignas de vida para as gerações atuais e futuras.

Tendo em vista a grande preocupação com o Meio Ambiente, esta pesquisa foi realizada com o objetivo de descobrir como as escolas estaduais de Floresta $(P) E$ vêm trabalhando as questões ambientais ao mesmo que buscou esclarecer e conscientizar gestores, professores e alunos sobre a importância de se trabalhar a educação ambiental em todo cotidiano escolar fazendo-se enxergar que a fonte de todos os recursos necessários para se viver estar bastante ameaçado devido ao consumo desenfreado e as novas tecnologias da população podendo levar o meio ambiente a destruição.

O trabalho iniciou-se com estudos, pesquisas bibliográficas e confecções de resumos para que se pudesse entender mais sobre a questão da educação ambiental, fazendo-se um recorte teórico do que seria necessário para aplicação do mesmo. Diante disto, a realização desta pesquisa foi descritiva com abordagem qualiquantitativa onde remeteu para verificação de como se dar o processo de ensino e aprendizagem no que diz respeito à questão ambiental e a sustentabilidade nas turmas de ensino médio das escolas públicas estaduais de Floresta. O questionário, do tipo questões objetivas foi o instrumento para a coleta de dados. O sujeito ao qual se destinou a pesquisa preencheu um termo de consentimento livre e esclarecido.

A população investigada foram professores, gestores e alunos das escolas públicas estaduais de Floresta (PE), onde foi obtida uma amostragem 
de $10 \%$ dos alunos e $30 \%$ dos educadores e gestores de cada escola pesquisada, num total de quatro escolas da sede, após conversa com os mesmos para esclarecer sobre a pesquisa, sua finalidade e importância. A coleta de dados foi analisada e separada de acordo com cada grupo: gestores, professores e alunos.

Após análise dos dados foram socializados os resultados obtidos em um seminário realizado no Auditório do Instituto Federal Sertão Pernambucano, Campus Floresta, com a presença de representação de todos os segmentos participantes da pesquisa, na ocasião foi distribuídos panfletos informativos sobre os cuidados que devemos ter com os recursos naturais e todas as questões ambientais.

\section{Análise dos Resultados obtidos com a Pesquisa de Campo}

$\mathrm{Na}$ pesquisa realizada com os gestores das quatro escolas, todos afirmam que a Educação Ambiental deve ser trabalhada diariamente, que em suas escolas realizam momentos de reflexão sobre o tema, e que realizam atividades de incentivo sobre a sustentabilidade e a preservação ambiental.

Com relação a metodologia utilizada pelos professores tem colaborado com o processo de Educação Ambiental, houve variações de respostas, conforme Figura 1.

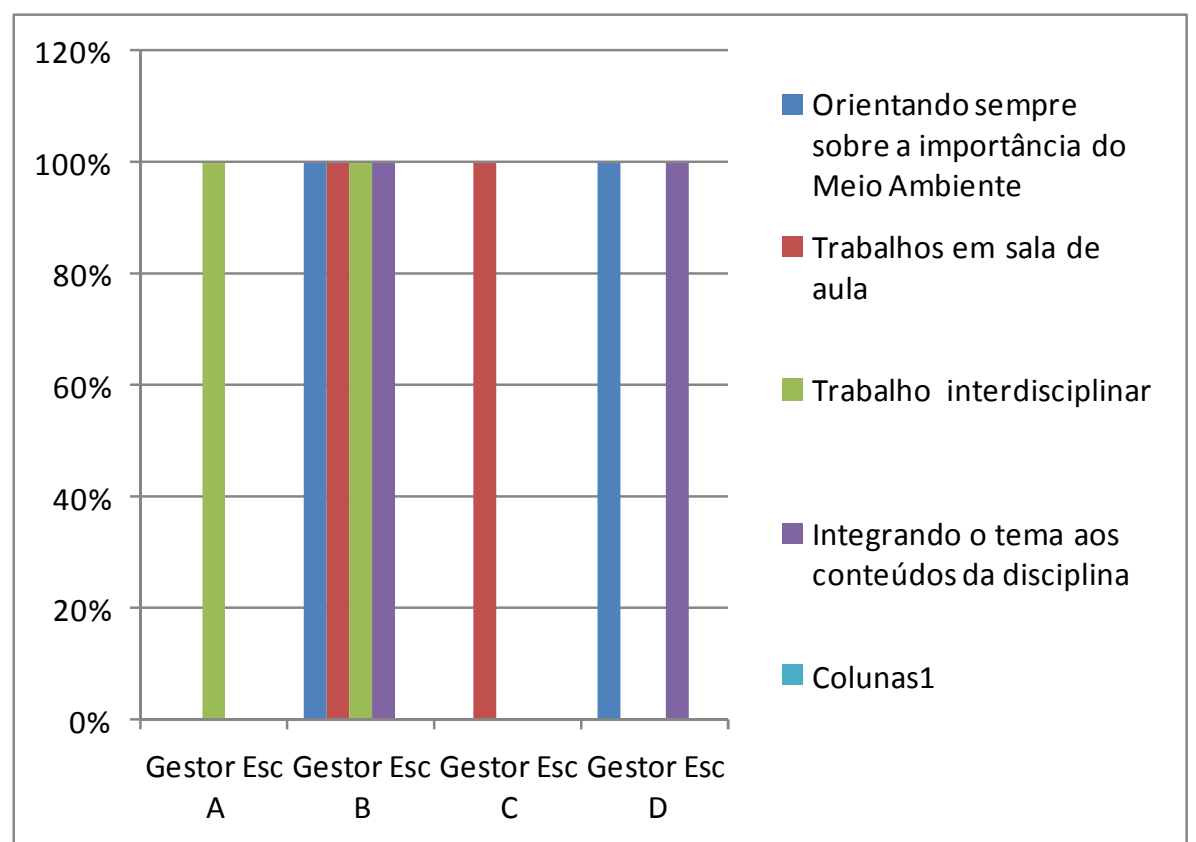

Figura 1 - Gráfico mostrando como os gestores percebem como a metodologia utilizada pelos professores tem contribuído com o Processo de Educação Ambiental.

$$
\text { Fonte: SÁ (2013) }
$$

Quanto a reciclagem, os gestores das Escolas B e D dizem que realizam a separação dos resíduos para reciclagem, já os das Escolas A e C não 
realizam separação. Os gestores das Escolas A, C e D, confessam que tem contribuído a nível local, regional e global com as questões ambientais, incentivando os servidores a participar de atividades de mobilização, enquanto que o gestor da Escola B diz que organiza oficinas e palestras relacionadas ao Meio Ambiente e Sustentabilidade. Os gestores colocam ainda que o Projeto Cultura de Paz, promovido pela Diocese de Floresta, proporcionou métodos para trabalhar a Educação Ambiental, facilitando o trabalho dos professores referentes ao tema.

$\mathrm{Na}$ opinião da maioria dos professores, a Educação Ambiental deve ser trabalhada diariamente. Em todas as escolas pesquisadas, os professores dizem que a escola na qual eles estão lotados realiza momentos para reflexão relacionada ao tema ambiental, coincidindo com as respostas dos gestores.

Os professores da Escola $A, B$ e $C$ relatam que sempre têm desempenhado seu trabalho contextualizando-o com ideias sustentáveis e a importância da preservação do Meio Ambiente, apenas os professores da Escola $D$ dizem que as vezes fazem essa contextualização.

Todos os professores das escolas pesquisadas relatam que a escola onde trabalham realiza atividades de incentivo a sustentabilidade e a preservação ambiental.

Ao serem indagados como a metodologia dos professores tem colaborado com o processo de Educação Ambiental, houve variações de respostas conforme Figura 2.

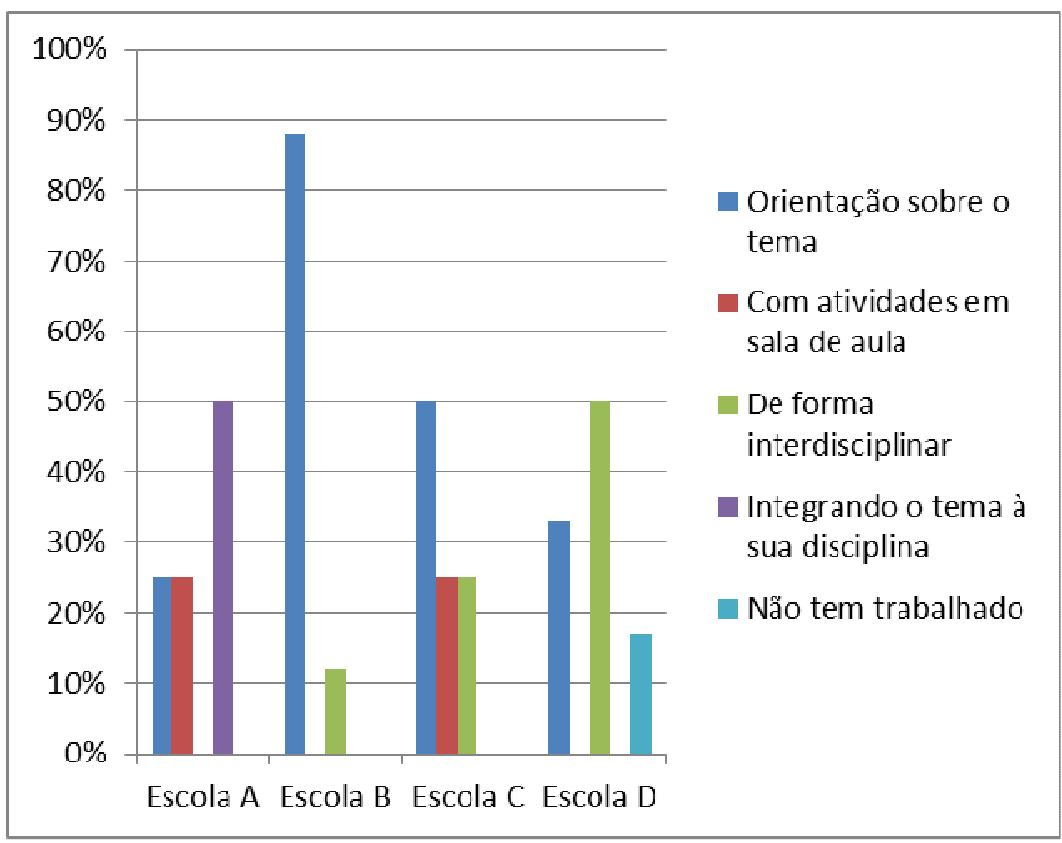

Figura 2 - Gráfico mostrando como os professores vêm de que forma a metodologia utilizada por eles tem contribuído com o Processo de Educação Ambiental. Fonte: SÁ (2013)

Quanto a reciclagem, $50 \%$ dos professores dizem que a escola não realiza a separação dos resíduos, e os outros $50 \%$ respondem que a escola realiza a separação, mas eles desconhecem o destino destes resíduos. 
Em se tratando das contribuições que os professores têm dado em relação ao Meio Ambiente e a Sustentabilidade a nível local, regional e global, surgem algumas ações, como: realização de projetos com o tema; contextualização; e organização de atividades de mobilização junto a escola.

A maioria dos professores afirma que o Projeto Cultura de Paz promovido pela Diocese de Floresta, facilitou o seu trabalho em relação às questões ambientais.

Em se tratando das respostas dos alunos, 90\% dizem que entende por Educação Ambiental, como sendo uma prática sobre o meio ambiente para a construção de uma sociedade sustentável. $60 \%$ relatam que a escola onde estudam incentiva práticas que levam a construção de valores socioambientais, enquanto que $40 \%$ não tem percebido este incentivo.

As atividades que a escola tem desenvolvido a cerca do tema, no sentido de motivar os alunos a preservar o meio ambiente, segundo $75 \%$ dos alunos têm sido atividades em sala de aula, de forma contextualizada, os demais dizem que através de palestras e oficinas.

Divergindo das respostas dos gestores e dos professores, $80 \%$ dos alunos afirmam que a sua escola não realiza a separação dos resíduos, relatando ainda que nunca expôs nenhuma ideia para contribuir para a sustentabilidade.

A maioria dos alunos afirma já terem trabalhado com algum tipo de reciclagem com algum tipo de material, dentre eles, a Figura 3 mostra.

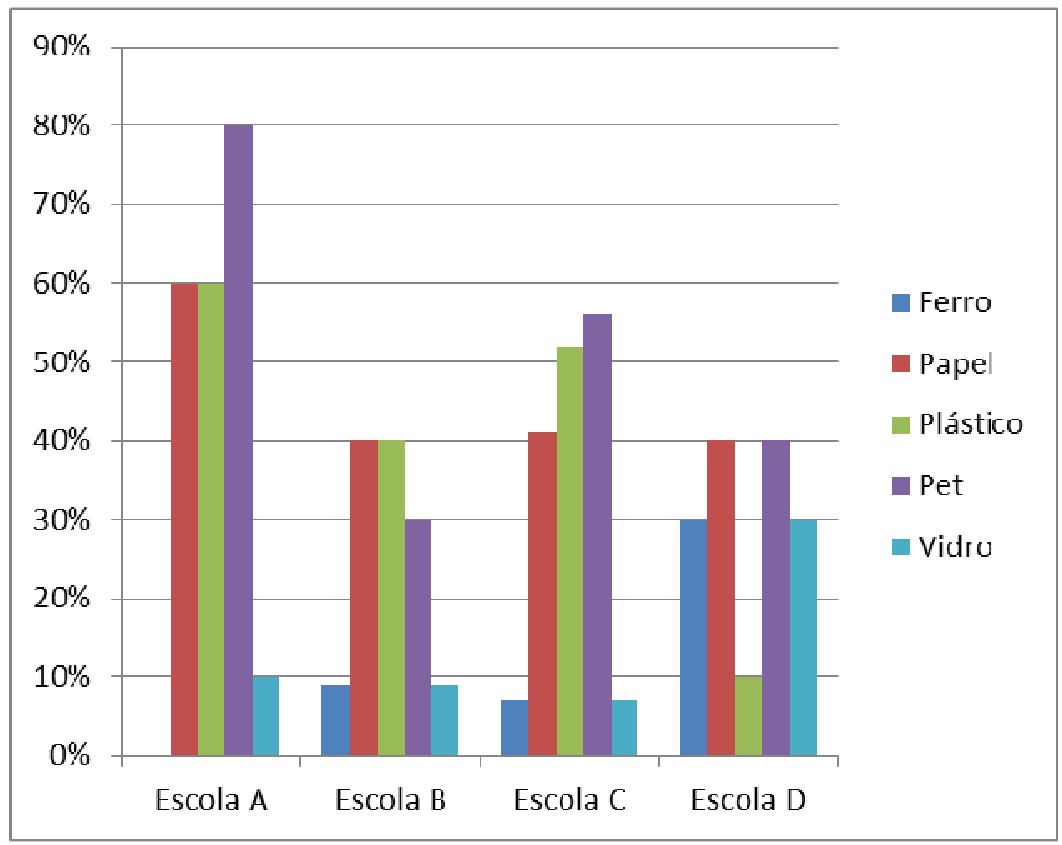

Figura 3 - Gráfico mostrando os materiais que os alunos já utilizaram para a reciclagem. Fonte: SÁ (2013). 
Todos os alunos pesquisados reconhecem a importância de se trabalhar às questões ambientais e a sustentabilidade, através de projetos com um trabalho interdisciplinar, diariamente. Ressaltam ainda, que conhecem 0 Projeto Cultura de Paz e acreditam que o mesmo trouxe contribuições importantes, facilitando o trabalho dos professores.

Percebe-se que as escolas envolvidas acreditam que a Educação Ambiental deve estar presente em todo cotidiano escolar para que os alunos aprendam sobre a necessidade de atribuir e construir novos valores voltados ao meio ambiente, tornando assim, cidadãos socioambientais, afirmam ainda que o tema está sendo trabalhado diariamente junto à disciplina de cada professor.

A questão é que esses dados colhidos mostraram que há controvérsia entre os gestores/professores e alunos. Enquanto os gestores e professores dizem fazer sempre trabalhos voltados a questão ambiental no dia a dia no ambiente escolar, parte dos alunos afirma não ocorrer este trabalho.

Os alunos apresentaram grande interesse sobre a Educação Ambiental e desenvolvimento sustentável, porém observa-se que a carência do tema é bastante, mesmo com a obrigatoriedade da Lei no 9.795/99 que estabelece que a Educação Ambiental deva estar presente, de forma articulada, em todos os níveis e modalidades do processo educativo, ainda há uma grande precariedade, pois a Lei e realidade andam longe uma da outra.

\section{Conclusões}

A pesquisa realizada mostra que parte dos alunos do Ensino Médio das Escolas Estaduais de Floresta - PE tem uma noção sobre a questão Ambiental. No entanto, faz-se perceber que gestores e professores dificilmente saem do discurso e partem para prática, há uma grande carência em projetos voltados ao meio ambiente e em continuações de trabalhos relacionados ao tema.

Entende-se ainda que, a maioria dos alunos tem interesse em aprender mais sobre Educação Ambiental. Sendo necessário afirmar que os gestores/professores tem clareza quanto à importância dessa temática, mas pouca consistência em relação à mesma. Percebe-se a necessidade de se incentivar diariamente na escola reflexões e práticas que levem todos a compreender as questões ambientais, para que se possam formar cidadãos com consciência ambiental, facilitando assim, sua vivência em sociedade.

Sabe-se que este é o caminho para que cada indivíduo mude de hábitos e assuma novas atitudes que levem à diminuição da degradação ambiental, promovam a melhoria da qualidade de vida e reduzam a pressão sobre os recursos ambientais. Mas este objetivo só será alcançado quando todos perceberem que este processo é algo que tem que ser entendido e realizado por cada um de nós. 


\section{AGRADECIMENTOS}

Ao Instituto de Tecnologia de Pernambuco e ao Instituto Federal Sertão Pernambucano por proporcionar o mestrado em Tecnologia Ambiental.

\section{Referências}

BRASIL, Lei no 9.795 de 27 de abril de 1999. Dispõe sobre Educação Ambiental, institui a política nacional de Educação Ambiental e dá outras providências. Brasília: MEC, 2007.

CARVALHO, Aloma et al.Jovens em ação! Ações para melhorar o ambiente e a qualidade de vida nas cidades.São Paulo: Melhoramentos, 2005.

EDUCAÇÃO AMBIENTAL: necessária para a sustentabilidade disponível em:<http://www.pga.pgr.mpf.gov.br/educacaoambiental $>$ Acesso em 15 de maio de 2013.

MEIO AMBIENTE disponível em: <http://www.suapesquisa.com> Acesso em 14 de jun de 2013.

EDUCAÇÃO AMBIENTAL disponível em: <http://www.brasilescola.com.br> Acesso em: 18 de jun de 2013.

LEFF, H. Saber Ambiental: Sustentabilidade, Racionalidade, Complexidade, Poder. 3. Ed. Rio de Janeiro: Vozes, 2008. 